\title{
There Is a Missing Ingredient in Diabetes Care Today
}

\author{
Aus Alzaid, MD
}

\section{Introduction}

A GROUP OF JUNIOR COLLEAGUES recently asked me what, after nearly 30 years of experience of caring for people with diabetes, I would consider as the single most important piece of advice to give to them as they launch into their new diabetes practice. It didn't take me long to find an answer. "Ensure you have good communication with your diabetes patients," I replied without trepidation.

To start with, communication and interpersonal skills of the physician are the heart and soul of our profession as medical doctors. The primary tool we use every day at work as physicians is that of consultation and interaction with the patient. It is equivalent to how a working baker would rely on an oven or a manual blacksmith on a hammer to fulfill his or her role. The medical interview is the main conduit we use to gather information, establish diagnosis, provide therapeutic instructions, and cultivate caring relationship with the patient. Historically, physicians are not sought for their depth of knowledge or academic record but are promptly recognized for their professional skills, personal care, and wisdom. Critically, effective consultation holds the key to successful medical management. ${ }^{1,2}$ In the case of people with diabetes, the role of communication takes on special clinical relevance.

\section{Diabetes is a Way of Life}

Diabetes is not an easy disease with which to live by any account. The condition is so intricately woven into the fabric of the patient's everyday life. Daily tasks are common, indefinite in nature, and time consuming and often infringe on the personal life of patients and their families. ${ }^{3,4}$ If you really look at it, having diabetes means you have an additional job to attend to every day. Imagine the reaction of your patients with hypothyroid disorder if you were to quiz them on the contents of every meal they consume or to expect them to check their thyroid-stimulating hormone level several times a day before deciding on the thyroxine dose to administer for the day! As physicians, we've grown used to giving orders to diabetes patients without necessarily realizing the extra burden those orders place on the person with diabetes.

Over $90 \%$ of the tasks inherent to diabetes management are done at home and under the direct control of the diabetes patient himself or herself, such as adhering to diet and exercise, testing blood glucose regularly, compliance with insulin injections, etc. The consultation visit therefore represents a window of opportunity for the physician to gain insight into the patient's performance and to coach and re-energize the patient toward goals set to reach optimal outcome. Given the limited time physicians generally spend with diabetes patients, estimated to be less than an hour a year, ${ }^{5,6}$ the clinic visit becomes an even more precious encounter. Effective communication is essential to motivate patients to adhere to medical therapy. I have often wondered how many physicians are aware of the positive impact that subtle words and small gestures can have on the well-being of diabetes patients and their metabolic control regardless of the medical therapy used.

\section{The 10 Commandments}

Here are the Golden Rules for effective communication in the diabetes clinic:

1. Recognize the importance of patient empowerment as being fundamental to diabetes management. ${ }^{7}$ The physician's role is to provide knowledge and expertise to enable patients make informed decisions. But, it is the patients themselves who are in charge of their destiny and the decisions and choices they make.

2. Use appropriate words and language when talking to patients with diabetes. Avoid invoking guilt, laying blame, or using incriminating tactics. Perceived benefits are better than perceived threats. ${ }^{8}$ Negative or careless language can be harmful and can demotivate patients. For an account on the role of language in diabetes management, read the excellent position statement published by Diabetes Australia. ${ }^{9}$

3. Allow collaborative care and shared decision making and "strike a deal" with the patient at each therapeutic juncture encountered. Heisler et al. ${ }^{10}$ showed that an informed communication style of the physician that included a participatory role for the patient in decision making resulted in significant improvement in patient self-care and glycemic control (glycated hemoglobin [HbA1c] improved by as much as $0.7 \%$ ). In another study, the improvement in $\mathrm{HbAlc}$ was found to be even greater $(1.5 \%)$ as a result of patient engagement

Prince Sultan Military Medical City, Riyadh, Saudi Arabia. 
in decision making. ${ }^{11}$ By contrast, a dominating and controlling style of communication by the healthcare provider resulted in poor metabolic control. ${ }^{12}$

4. Be practical and seek realistic goals. Focus on the achievable. Life is not about HbA1c level for every diabetes patient or every time for the regular patient attending the clinic.

5. Be nonjudgmental. Obese patients were less likely to lose weight if they felt the attending physician was in some way judgmental about their weight. ${ }^{13}$

6. Consider cultural issues, religious beliefs, and personal values of the patient. With some individuals and in certain parts of the world, religious beliefs are dearly held and may even take precedence over other issues in life. This can present a delicate situation to the unwary practitioner who may need to tread carefully between respecting personal values of the patient, on the one hand, and not compromising medical care provided, on the other. ${ }^{14}$

7. Reward effort, not just outcome. Even modest encouragement can inspire patients to do more for their cause.

8. Stay tuned to the patient's feelings and pick up the clues early. On average, a diabetes patient drops 2.6 clues per clinic visit. ${ }^{15}$ Subtle hints can be related to anything from loneliness at home to shortage of money. Although the physician does not have to solve every problem, an empathic response to the patient's concerns can improve clinic dynamics and change outcome. Furthermore, missed clues mean lost opportunities and, interestingly, lead to longer, not shorter, clinic visits. ${ }^{15}$

9. Use visual tools as much as possible: make a simple drawing or show the patient a relevant graph or picture to facilitate understanding and enhance motivation. Levetan et al. ${ }^{16}$ showed that the mere provision of a poster of HbA1c values marked with target goals improved metabolic control significantly in the patients tested. In another study, the Vision Study, investigators showed that graphic display of self-monitored blood glucose data significantly improved metabolic control, with an impressive $0.93 \%$ reduction in $\mathrm{HbA} 1 \mathrm{c}$ in the type 2 diabetes patients studied. ${ }^{17}$ Seeing is believing for many patients.

10. Does your patient comprehend and remember the instructions given at the clinic? Patients have poor recall of decisions made at the clinic and tend to forget as much as $50 \%$ of what they are told by their physician. ${ }^{18-20}$ To explore the benefits of checking patient comprehension and recall, Schillinger et al. ${ }^{21}$ listened to audiotapes taken at outpatient settings and found a significant improvement in glycemic control in patients whose physicians applied this simple interactive strategy compared with those who were not assessed for comprehension and recall. Asking your patient to restate and summarize your instructions makes good sense and is obviously therapeutically rewarding.

\section{Communication: A Natural Secret Remedy for Diabetes}

The tips cited above are not meant to be a call for physicians to just "be nicer" to their patients or a ploy to improve customer service at the diabetes clinic. Rather, they emphasize the point that the quality of doctor-patient interaction is an important determinant of glycemic control and healthcare outcome for people with diabetes. It is interesting how little HbA1c level has changed over recent years despite the introduction of numerous antidiabetes agents and advanced diabetes technologies. The reduction in HbAlc level observed in the adult U.S. diabetes population over the period of 1988-2006 amounted to a modest $0.5 \% .^{22}$ Perhaps, something else is missing in diabetes care strategies. Communication may not have the gloss or glamor associated with a new pharmaceutical product, but clinically it deserves our attention as a distinct therapy for diabetes that is comparable in effect (if not better) to that seen with use of dipeptidyl peptidase-4 inhibitors or introduction of insulin pump therapy. Communicative support by the physician can also raise the patient's morale and personal satisfaction. Needless to say, communication is accessible to all physicians and is free of charge to all patients. Furthermore, communication has no cardiovascular risk or any other side effects to consider and so will not require regulatory body approval before release into the "markets." Communication should, in my opinion, be considered a universal first-line therapy in any future guidelines made for the treatment of diabetes. We should also train physicians on the art and craftsmanship of communication with people with diabetes. Research studies and collaborative work with behavioral scientists should also be encouraged to establish the full benefits of communication in diabetes practice. $^{23-25}$ It is probably high time that professional diabetes bodies followed suit with the example of the Diabetes Australia and embraced the role of communication as an important adjunct therapy in diabetes management. The industry too has an obligation to package and support the idea of communication as a good cause to pursue on behalf of people with diabetes. Communication is a natural secret weapon we have for the treatment of diabetes. It should not be kept secret anymore.

\section{References}

1. Stewart MA: Effective physician-patient communication and health outcomes: a review. Can Med Assoc J 1995;152: 1423-1433.

2. Ha JF, Longnecker N: Doctor-patient communication: a review. Ochsner J 2010;10:38-43.

3. Nicolucci A1, Kovacs Burns K, Holt RI, Comaschi M, Hermanns N, Ishii H, Kokoszka A, Pouwer F, Skovlund SE, Stuckey H, Tarkun I, Vallis M, Wens J, Peyrot M; DAWN2 Study Group: Diabetes Attitudes, Wishes and Needs second study (DAWN2 ${ }^{\mathrm{TM}}$ ): cross-national benchmarking of diabetesrelated psychosocial outcomes for people with diabetes. Diabet Med 2013;30:767-777.

4. Russell LB, Suh DC, Safford MA: Time requirements for diabetes self-management: too much for many? J Fam Pract 2005;54:52-56.

5. Barnes CS, Ziemer DC, Miller CD, Doyle JP, Watkins C Jr, Cook CB, Gallina DL, el-Kebbi I, Branch WT Jr, Phillips LS: Little time for diabetes management in the primary care setting. Diabetes Educ 2004;30:126-135.

6. Chen LM, Farwell WR, Jha AK: Primary care visit duration and quality: does good care take longer? Arch Intern Med 2009;169:1866-1872.

7. Anderson RM, Funnell MM: Patient empowerment: myths and misconceptions. Patient Educ Counsel 2010;79:277282. 
8. Dimatteo MR: The role of effective communication with children and their families in fostering adherence to pediatric regimens. Patient Educ Couns 2004;55:339-344.

9. Speight J1, Conn J, Dunning T, Skinner TC; Diabetes Australia: Diabetes Australia position statement. A new language for diabetes: improving communications with and about people with diabetes. Diabetes Res Clin Pract 2012; 97:425-431.

10. Heisler M, Cole I, Weir D, Kerr EA, Hayward RA: Does physician communication influence older patients' diabetes self-management and glycemic control? Results from the Health and Retirement Study (HRS). J Gerontol A Biol Sci Med Sci 2007;62:1435-1442.

11. Greenfield S, Kaplan SH, Ware JE Jr, Yano EM, Frank HJ: Patients' participation in medical care: effects on blood sugar control and quality of life in diabetes. J Gen Intern Med 1988;3:448-457.

12. Street RL Jr, Piziak VK, Carpentier WS, Herzog J, Hejl J, Skinner G, McLellan L: Provider-patient communication and metabolic control. Diabetes Care 1993;16:714-721.

13. Gudzune KA, Bennett WL, Cooper LA, Bleich SN: Perceived judgment about weight can negatively influence weight loss: a cross-sectional study of overweight and obese patients. Prev Med 2014;62C:103-107.

14. Alzaid A: Diabetes: a tale of two cultures. Br J Diabetes Vasc Dis 2012;12:57-59.

15. Levinson W, Gorawara-Bhat R, Lamb J: A study of patient clues and physician responses in primary care and surgical settings. JAMA 2000;284:1021-1027.

16. Levetan CS, Dawn KR, Robbins DC, Ratner RE: Impact of computer-generated personalized goals on $\mathrm{HbA}_{1 \mathrm{c}}$. Diabetes Care 2002;25:2-8.

17. Weissmann J, Mueller A, Pralle K, Ruessmann H, Gregersen B, Messinger D, Amann-Zalán I: Informationsmanagement verbessert signifikant die glykämische Stoffwechseleinstellung bei Typ-2-Diabetes: Ergebnisse der multizentrischen, nichtinterventionellen VISION Studie. Diabetol Stoffwechsel 2012; 7:P_112.10.1055/s-0032-1314609.
18. Skinner TC, Barnard K, Cradock S, Parkin T: Patient and professional accuracy of recalled treatment decisions in out-patient consultations. Diabet Med 2007;24:557-560.

19. Crane JA: Patient comprehension of doctor-patient communication on discharge from the emergency department. J Emerg Med 1997;15:1-7.

20. Bertakis KD: The communication of information from physician to patient: a method for increasing patient retention and satisfaction. J Fam Pract 1977;5:217-222.

21. Schillinger D, Piette J, Grumbach K, Wang F, Wilson C, Daher C, Leong-Grotz K, Castro C, Bindman AB: Closing the loop: physician communication with diabetic patients who have low health literacy. Arch Intern Med 2003;163: 83-90.

22. Centers for Disease Control and Prevention: Mean/Median A1c Among Adults with Diagnosed Diabetes, United States, 1988-1994 to 1999-2006. www.cdc.gov/diabetes/statistics/ a1c/detailed_a1c_mean_median_educ.htm (accessed March 27, 2014).

23. Griffin SJ, Kinmonth AL, Veltman MW, Gillard S, Grant J, Stewart M: Effect on health-related outcomes of interventions to alter the interaction between patients and practitioners: a systematic review of trials. Ann Fam Med 2004; 2:595-608.

24. van Dam HA, van der Horst F, van den Borne B, Ryckman $\mathrm{R}$, Crebolder H: Provider-patient interaction in diabetes care: effects on patient self-care and outcomes. A systematic review. Patient Educ Couns 2003;51:17-28.

25. Speight J: Managing diabetes and preventing complications: what makes the difference? Med J Aust 2013;198:16-17.

Address correspondence to: Aus Alzaid, MD

Prince Sultan Military Medical City P.O. Box 7897

Riyadh 11159, Saudi Arabia

E-mail: drausalzaid@hotmail.com 